\title{
As aposentadorias e pensões e a concentração dos rendimentos domiciliares per capita no Brasil e na sua área rural: 1981 a 2003.
}

\author{
Carlos Roberto Ferreira* \\ Solange de Cássia Inforzato de Souza**
}

Resumo: Este trabalho tem como objetivo analisar a participação e a contribuição do rendimento domiciliar “aposentadorias e pensões” para a desigualdade da distribuição do rendimento domiciliar per capita no Brasil e Brasil Rural, no período de 1981 a 2003. Para isso, revisa a literatura sobre concentração de renda e previdência social, e utiliza a metodologia de decomposição do índice de Gini levando em consideração os componentes: rendimento do trabalho principal, rendimento de outros trabalhos, aposentadorias e pensões, doações, rendimentos de aluguel e outros rendimentos (juros, dividendos etc.). Destaca-se, nos resultados, a crescente participação das aposentadorias e pensões nos anos 1990 em relação à década anterior, com maior intensidade no Brasil rural, explicada pelas políticas sociais e econômicas do período. A contribuição dessa parcela de rendimento domiciliar para a concentração de renda é significativa para o Brasil em nove dos 18 anos analisados, e para a área rural a partir da década de 1990.

Palavras-chave: Previdência Social Rural; Aposentadorias e pensões; Concentração de renda.

Classificação JEL: D31; D63.

*Doutor pela ESALQ/USP. robert@uel.br

**Doutora pela PUC/SP. solangecassia@uol.com.br 
Abstract: This work has as objective to analyze the participation and the contribution of the household income "retirements and pensions" for the inequality of the distribution of the per capita household income in Brazil and Rural Brazil, in the period from 1981 to 2003. For that, it revises the literature about concentration of income and social welfare in the country, and it uses the Gini index components decomposition methodology: revenue of the main work, revenue of other works, retirements and pensions, donations, rent revenues and other revenues (interests, dividends, etc.). It stands out, in the results, the growing participation of the retirements and pensions and in the 1990's in relation to the previous decade, with larger intensity in rural Brazil, explained by the social and economic policies of the period. The contribution of that portion of household income for the concentration of income is significant to Brazil in 9 of the 18 analyzed years, and to rural Brazil, starting from the decade of 1990.

Key words: Rural Social Welfare; Retirements and pensions; Concentration of income.

JEL Classification: D31; D63.

\section{Introdução}

O debate sobre a Previdência social brasileira intensificou-se a partir da segunda metade da década de 1990, em conseqüência dos seus significativos e crescentes resultados deficitários, particularmente evidenciados pelo comportamento do resultado financeiro do Regime Geral da Previdência Social (RGPS), para o setor privado (32 bilhões de Reais em 2004) e do Regime Jurídico Único (RJU), para o funcionalismo federal (31,7 bilhões de Reais em 2004). As despesas previdenciárias representaram, em 2004, 9,7\% do Produto Interno Bruto, sendo que o total dos gastos sociais diretos do governo federal compreendeu 14,2\% do PIB. A desagregação dos dados indica que as despesas previdenciárias do RGPS significaram 7,35\% do PIB em 2004 (em 1998 esse número era de $5,63 \%$ ) e do RJU 2,26\% (em 1998 o valor era $2,27 \%)^{1}$.

\footnotetext{
${ }^{1}$ Ver Brasil (2005)
} 
Os constrangimentos financeiros da previdência social são atribuídos a um conjunto de fatores que derivam do seu quadro institucional, gerencial e estrutural. O complexo institucional previdenciário está assentado no modelo de repartição simples, cuja lógica pressupõe que as contribuições pagas pelos trabalhadores ativos destinam-se a cobrir os gastos com benefícios dos inativos. O comportamento das variáveis demográficas, que mostra aumento da expectativa de sobrevida da população e queda da fecundidade, as mudanças na composição do mercado de trabalho, com redução das contribuições previdenciárias, e a Constituição de 1988 que ampliou os benefícios, comprometem o sistema previdenciário, ao mesmo tempo em que o país revela, historicamente, expressiva concentração de renda.

A despeito disso, a previdência social do Brasil apresenta-se como um dos mais importantes instrumentos de política pública e base de sustentação da economia de um grande número de municípios brasileiros de baixa renda.

Este trabalho analisa a participação das aposentadorias e pensões no rendimento domiciliar e a magnitude de sua contribuição para a concentração de renda no Brasil e no Brasil rural, no período de 1981 a 2003, através da decomposição do índice de Gini.

Na seção seguinte são descritos os procedimentos metodológicos para o desenvolvimento da pesquisa. A terceira seção organiza a revisão de literatura sobre a concentração de renda e previdência social no Brasil, seus antecedentes e experiência recente, para, na quarta seção, analisar os resultados da decomposição do índice de Gini. Na quinta seção estão as considerações finais.

\section{Base de dados}

O presente estudo tem por base as informações coletadas nas Pesquisas Nacionais por Amostra de Domicílios (PNAD), no período de 1981 a 2003. A PNAD tem periodicidade anual desde 1971, sendo interrompida por ocasião dos Censos Demográficos (1970, 1980, 1991 e 2000). Trata-se de um levantamento anual realizado por meio de uma amostra dos domicílios que abrange todo o país, exceto a área rural dos estados da antiga região Norte (Acre, Amapá, Amazonas, Pará, Rondônia e Roraima). Para

RER, Rio de Janeiro, vol. 45, no 04, p. 985-1011, out/dez 2007 - Impressa em novembro 2007 
as pesquisas da década de 1990 e anos posteriores, essa abrangência geográfica foi mantida, ou seja, a PNAD continuou a cobrir todo o país, com exceção da área rural dessas seis unidades da federação.

Por essa pesquisa são investigados, de forma permanente, os temas habitação, rendimento e trabalho, associados a aspectos demográficos e educacionais, bem como outros assuntos de caráter demográfico, social e econômico com periodicidade variável. É uma coleta oficial de dados, realizada sob a responsabilidade do Departamento de Emprego e Rendimento da Diretoria de Pesquisa da Fundação Instituto Brasileiro de Geografia e Estatística (IBGE).

A comparação dos resultados da PNAD a partir de 1992 com os das décadas anteriores deve levar em conta que a classificação das áreas urbanas e rurais é feita de acordo com a legislação vigente por ocasião dos censos demográficos. Dessa forma, manteve-se a delimitação das áreas urbanas e rurais no período intercensitário, mesmo que a legislação a tenha alterado. Para as pesquisas da PNAD de 1981 a 1990, utilizou-se a classificação vigente por ocasião do Censo Demográfico de 1980; para as pesquisas da PNAD de 1992 a 1999, utilizou-se a classificação vigente por ocasião do Censo Demográfico de 1991 e para a pesquisa da PNAD de 2001, 2002 e 2003, utilizou-se a classificação vigente por ocasião do Censo Demográfico de 2000. Por razões excepcionais, não foi realizada a pesquisa em 1994. Dessa forma, as estatísticas por situação urbana e rural não captam integralmente a sua evolução, sendo que as diferenças se intensificam à medida que os resultados obtidos se afastam do ano de realização do Censo Demográfico.

Ressalta-se também que, para as PNADs de 1992 a 1996, foram utilizados os fatores de expansão corrigidos com base na contagem populacional e divulgados juntamente com os microdados da PNAD de 1997.

Neste estudo, não são consideradas as informações das PNADs referentes a 1982 e 1987. A decisão de exclusão referente a 1982 é decorrente da diferença de procedimento na coleta dos dados neste ano (em 12 semanas de referência), em cujo intervalo houve alteração do valor do salário mínimo, enquanto nos demais anos do período considerouse uma semana de referência. Quanto a 1987, a razão de exclusão decorre de não ter sido possível ler corretamente o arquivo de dados disponíveis.

RER, Rio de Janeiro, vol. 45, no 04, p. 985-1011, out/dez 2007 - Impressa em novembro 2007 
Foram utilizados ${ }^{2}$ dados individuais das PNADs de 1981, 1983, 1984, 1985, 1986, 1988, 1989, 1990, 1992, 1993, 1995, 1996, 1997, 1998, 1999, 2001, 2002 e 2003, fornecidas pelo IBGE, através de CD-ROM anual.

O procedimento metodológico adotado pelo IBGE implica que cada pessoa da amostra representa um determinado número de pessoas da população. Os dados individuais são fornecidos com o peso ou fator de expansão de cada indivíduo. Isso permite que os cálculos sejam elaborados ponderando-se cada observação pelo respectivo peso. Todos os cálculos, neste trabalho, foram feitos considerando o peso ou fator de expansão de cada domicílio da amostra da PNAD, fornecido pelo IBGE, analisados apenas os domicílios particulares permanentes com declaração do rendimento domiciliar. Domicílios com rendimentos não declarados foram excluídos da análise.

As informações das PNADs são de boa qualidade, mas é preciso observar algumas características da natureza desses dados, as quais são restrições que precisam ser levadas em consideração na análise dos resultados, conforme alerta Hoffmann (1988 e 2002a).

De acordo com as notas metodológicas do IBGE (2001), "considerou-se como rendimento mensal domiciliar a soma dos rendimentos mensais dos moradores do domicílio, exclusive os das pessoas cuja condição no domicílio fosse pensionista, empregado doméstico ou parente do empregado doméstico". Para se obter o rendimento domiciliar per capita, dividiu-se o rendimento mensal domiciliar pelo número de pessoas do domicílio, excluindo pensionistas, empregados domésticos e seus parentes.

Os rendimentos de aposentadorias e pensões são aqueles pagos pelo governo federal ou por instituto de previdência, entidades seguradoras ou fundos de pensão; e finalmente, juros, dividendos etc., são decorrentes de aplicações financeiras em ativos financeiros de renda fixa, caderneta de poupança, além de programas como o bolsa-família, renda mínima e outros. (IBGE,2003)

As análises foram feitas para o Brasil como um todo e apenas para os residentes nas áreas rurais. Cabe ressaltar que o "rural" refere-se apenas à situação do domicílio, e não à origem dos rendimentos.

${ }^{2}$ Para maiores detalhes, ver Ferreira (2003).

RER, Rio de Janeiro, vol. 45, no 04, p. 985-1011, out/dez 2007 - Impressa em novembro 2007 


\subsection{Metodologia}

Para o desenvolvimento deste trabalho, utilizou-se a decomposição do Índice de Gini para analisar a contribuição das aposentadorias e pensões para a desigualdade da distribuição do rendimento domiciliar per capita no Brasil e no Brasil Rural, ao longo das décadas de 1980 e 1990 e anos posteriores, 2001, 2002 e 2003. Essa decomposição da desigualdade considera os vários componentes que se somam para formar os rendimentos domiciliares ${ }^{3}$ : trabalho principal, outros trabalhos, aposentadorias e pensões, aluguéis, doações, juros etc.

\subsubsection{Decomposição do índice de Gini}

A metodologia de decomposição do coeficiente de Gini utilizada neste trabalho está baseada em Pyatt et al. (1980) ${ }^{4}$. Inicialmente, pressupõe-se que há $n$ pessoas e que $z_{i}$ e $t_{i}$ são duas variáveis quaisquer observadas nas pessoas com $(i=1,2, \ldots, n)$. As pessoas terão uma posição de ordem de acordo com $t_{i}$ : a posição da pessoa na colocação $i$ será denominada $r\left(t_{i}\right)$, com a convenção de que $r\left(t_{i}\right)=1$ para a pessoa com o $t_{i}$ menor e $r\left(t_{i}\right)=n$ para a pessoa com o maior $t_{i}$. Se duas ou mais pessoas tiverem o mesmo valor para $t_{i}$, para cada uma delas será dada a média das posições que essas pessoas poderão ter se houver uma diferença infinitesimal entre elas. Dessa forma, a média de todas as posições $r\left(t_{i}\right)$ é dada por:

$$
\bar{r}=\frac{1}{n} \sum_{i=1}^{n} r\left(t_{i}\right)=\frac{(n+1)}{2}
$$

A média das posições é, portanto, independente do critério de "posicionamento" $t_{i}$ que é dado.

Admite-se que o valor médio de $z_{i}$ é positivo, isto é,

$$
\bar{z}=\frac{1}{n} \sum_{i=1}^{n} z_{i}>0
$$

\footnotetext{
${ }^{3}$ Um exemplo numérico de decomposição pode ser encontrado em Ferreira (2003). ${ }^{4}$ Essa metodologia já foi utilizada por muitos autores, podendo-se citar Fei et al. (1978), Ercelawn (1984), Mariano; Lima (1998), Neder (2001), Hoffmann (2002a , 2002b e 2003).
} 
Note-se que $z_{i}$ não necessita ser positivo para todo $i$.

Dado $\bar{z}$, pode-se também definir:

$$
\pi_{i}=\frac{z_{i}}{n \bar{z}}
$$

para cada pessoa. De (2) e (3) tem-se que a soma dos $n$ valores de $\pi_{i}$ é igual a 1.

A curva de concentração de $z_{i}$ em relação a $t_{i}$ mostra como os valores acumulados dos $\pi_{i}$ variam em função de $\frac{r\left(t_{i}\right)}{n}$, tendo-se previamente ordenado as pessoas conforme valores crescentes de $r\left(t_{i}\right)$. Note-se que a curva de concentração não precisa ser monotonicamente crescente. A curva pode ficar acima do bissetor do primeiro quadrante. Se houver valores negativos de $z_{i}$, a curva pode ficar abaixo do eixo das abcissas.

A razão de concentração de $z$ em relação a $t$, indicada por $C(z \mid t)$, é definida como um menos duas vezes a área entre a curva de concentração e o eixo das abcissas. Cabe ressaltar que áreas delimitadas pela curva de concentração abaixo do eixo das abcissas são negativas.

Observa-se que a área abaixo da curva de concentração pode ser obtida através da soma das áreas de $n$ trapézios verticais, cada um com altura de $\left(\frac{1}{n}\right)$, isto é, como:

$$
\begin{aligned}
& \delta=\frac{1}{2} \cdot \frac{1}{n}\left[\pi_{1}+\sum_{i=2}^{n}\left(\sum_{j=1}^{i-1} \pi_{j}+\sum_{j=1}^{i} \pi_{j}\right)\right] \\
& \delta=\frac{1}{2} \cdot \frac{1}{n} \sum_{i=1}^{n} \pi_{i}[1+2(n-i)]
\end{aligned}
$$

em que o subscrito $i$ refere-se à posição de ordem da pessoa, ou seja, $i=r\left(t_{i}\right)$.

De (4) tem-se que a razão de concentração é:

$$
C(z \mid t)=1-\frac{1}{n} \sum_{i=1}^{n} \pi_{i}[1+2(n-i)]
$$

Lembrando a expressão (1), após algumas transformações algébricas verifica-se que

RER, Rio de Janeiro, vol. 45, no 04, p. 985-1011, out/dez 2007 - Impressa em novembro 2007 


$$
C(z \mid t)=\frac{2}{n} \sum_{i=1}^{n} \pi_{i}\left[r\left(t_{i}\right)-\bar{r}\right]
$$

ou

$$
C(z \mid t)=2 \operatorname{cov}[\pi(z), r(t)]
$$

em que $\operatorname{cov}(a, b)$ é a covariância entre as variáveis $a$ e $b$. Utilizando (3), segue-se que

$$
\begin{aligned}
& C(z \mid t)=2 \operatorname{cov}\left[\left(\frac{z}{n \bar{z}}\right), r(t)\right] \\
& \text { ou } \\
& C(z \mid t)=\frac{2}{n \bar{z}} \operatorname{cov}[z, r(t)]
\end{aligned}
$$

Se a variável $z$ for não-negativa $\left(z_{i} \geq 0\right.$ para todo $\left.i\right)$, verifica-se que a área abaixo da curva de concentração varia de $(2 n)^{-1}$ a $1-(2 n)^{-1}$, de maneira que

$$
\frac{1}{n}-1 \leq C(z \mid t) \leq 1-\frac{1}{n} .
$$

No caso particular em que a própria variável $z$ for utilizada para ordenar os valores, isto é, se $t=z$, a curva de concentração passa a ser a curva de Lorenz da distribuição de $z$ e a razão de concentração é o respectivo índice de Gini.

Se $y_{i}$ é a renda domiciliar per capita e as pessoas estiverem ordenadas conforme o valor dessa mesma variável, o índice de Gini da renda domiciliar per capita é

$$
G(y)=C(y \mid y)=\frac{2}{n \bar{z}} \operatorname{cov}[y, r(y)]
$$

Se $x_{i k}$ é a $k$-ésima parcela (por exemplo, a aposentadoria) da renda domiciliar per capita $y_{i}$, então:

$$
y_{i}=\sum_{k=1}^{m} x_{i k} \text { para }
$$

em que a renda total é constituída por $m$ parcelas $(k=1, \ldots, m)$. Segue-se que

RER, Rio de Janeiro, vol. 45, no 04, p. 985-1011, out/dez 2007 - Impressa em novembro 2007 
$\bar{y}=\sum_{k=1}^{m} \bar{x}_{k}$

em que $\bar{x}_{k}$ é a média de $x_{i k}$ para as $n$ pessoas.

Substituindo (9) em (8), tem-se:

$G(y)=\frac{2}{n \bar{z}} \operatorname{cov}\left[\sum_{k} x_{k}, r(y)\right]$

Lembrando (7), verifica-se que

$$
G(y)=\sum_{k=1}^{m} \phi_{k} C\left(x_{k} \mid y\right)
$$

em que:

$\phi_{k}=\frac{\bar{x}_{k}}{\bar{y}}$

Note-se que $\phi_{k}$ é a participação da $k$-ésima parcela na renda total.

É interessante verificar como a razão de concentração de $x_{k}$ em relação a $y$ está associada com o índice de Gini de $x_{k}$, que é dado por

$$
G\left(x_{k}\right)=\frac{2}{n \bar{x}_{k}} \operatorname{cov}\left[x_{k}, r\left(x_{k}\right)\right]
$$

Usando (7), tem-se:

$$
\frac{C\left(x_{k} \mid y\right)}{G\left(x_{k}\right)}=\frac{\operatorname{cov}\left[x_{k}, r(y)\right]}{\operatorname{cov}\left[x_{k}, r\left(x_{k}\right)\right]}=R\left(y, x_{k}\right)
$$

$R\left(y, x_{k}\right)$ é denominada razão de correlação de ordem, cabendo ressaltar que não é um coeficiente de correlação de ordem. A expressão (14) mostra que a razão será igual a um somente se:

$$
r(y)=r\left(x_{k}\right)
$$

ou seja, somente se as pessoas tiverem o mesmo ordenamento com respeito à parcela de renda $k$ e com respeito à renda domiciliar per capita.

Para obter $G\left(x_{k}\right)$, as pessoas são ordenadas conforme valores crescentes de $x_{i k}$. Em geral, o ordenamento será diferente no cálculo de 
$C\left(x_{k} \mid y\right)$, quando as pessoas são ordenadas pelo valor de $y_{i}$. É claro que o valor acumulado dos $x_{i k}$ até uma posição $h$ será mínimo quando a ordenação tiver sido feita conforme os próprios valores de $x_{i k}$. Em outras palavras, a curva de concentração de $x_{k}$ em relação a $y$ nunca poderá ficar abaixo da curva de Lorenz de $x_{k}$. Conseqüentemente, a razão de concentração de $x_{k}$ em relação a $y$ não pode exceder o índice de Gini de $x_{k}$, isto é,

$$
\frac{C\left(x_{k} \mid y\right)}{G\left(x_{k}\right)}=R\left(y, x_{k}\right)=R_{k} \leq 1 \text {. }
$$

Esse resultado também poderia ser obtido considerando que

$\operatorname{cov}[z, r(z)] \geq \operatorname{cov}[z, r(t)]$ para todo $t$.

Hoffmann (2002a) observa que, na expressão (11), se todas as razões de concentração tivessem o mesmo valor, esse seria também o valor de $G(y)$. Dessa forma, ele considera que um componente $x_{i k}$ contribui para aumentar a desigualdade quando $C\left(x_{k} \mid y\right)>G(y)$. Quando $C\left(x_{k} \mid y\right)<G(y)$, o componente $x_{i k}$ já está contribuindo para reduzir a desigualdade em relação àquela situação hipotética de igualdade das razões de concentração.

\section{A previdência social no Brasil}

A origem da previdência social no Brasil remonta à criação de Caixas de Aposentadorias e Pensões (CAPs) por categoria ocupacional ou empresa - o marco é a lei Elói Chaves, de 1923, sendo as CAPs referentes aos empregados de empresas ferroviárias, dos portuários e marítimos, e outros, de modo que em 1921 já haviam 183 CAPs no país.

Após a experiência dos anos 20, as caixas são substituídas pelos IAPs (Institutos de Aposentadorias e Pensões) sob o regime de capitalização, que incorporavam setores urbanos organizados dos trabalhadores, segundo a categoria profissional, centralizados no governo federal. ${ }^{5}$

Embora tendo centralidade na agenda política da previdência social,

\footnotetext{
${ }^{5}$ Entre 1933 e 1945 foram criados sete IAPs - marítimos, industriários, transportes de carga, bancários, comerciários, estivas e servidores do estado.
}

RER, Rio de Janeiro, vol. 45, no 04, p. 985-1011, out/dez 2007 - Impressa em novembro 2007 
a proteção social no Brasil não logrou êxito no sentido de universalização dos benefícios até a primeira metade dos anos 60. Por outro lado, foram importantes para o desenvolvimento industrial pós 30, seja em sua fase de industrialização restringida (1930/1955) seja em sua fase de boom (1956/1961).

O período pós 1964 foi, para o sistema de proteção e para a previdência social, um marco de rompimento com o padrão histórico, reformando a previdência social sob a perspectiva da unificação e universalização dos benefícios, financiada por contribuições sociais dos trabalhadores e gerida pelo regime de repartição simples ${ }^{6}$. No período da imaginação reformista (1964/1967) na economia brasileira foram gestados os formatos institucional e financeiro da política social brasileira. Na previdência social, destaca-se, sob resistência de alguns Institutos, a unificação dos IAPs, materializada no INPS (Instituto Nacional de Previdência Social), em 1967.

Além dos condicionantes políticos, os fatores econômicos que influenciaram a nova concepção de proteção e previdência social foram o próprio contexto econômico e a política econômica do PAEG (Plano de Ação Econômica do Governo), centrada na estabilidade de preços e reformas institucionais, que visavam ampliar o sistema de financiamento da economia e reduzir gastos sociais públicos, que obstruíam a industrialização pesada no país e pressionavam o orçamento fiscal.

A estratégia econômica adotada influenciou decisivamente os rumos da reforma previdenciária entre 1964 e 1967, pois ao conflitar com os objetivos do PAEG, a crise financeira do complexo previdenciário, agravada nos anos 60, passou a ser também uma questão econômica, justificando intervenções saneadoras, Em parte, a unificação dos institutos previdenciários foi impulsionada por objetivos racionalizadores, visando ao estabelecimento de critérios gerais de economicidade. (Braga; Paula, apud Fagnani, 1997)

A fase de crescimento econômico de 1968/73 impulsionou a consolidação da unificação previdenciária e fortalecimento de sua base financeira. Há uma expansão da cobertura, sublinhando, em 1971, o

${ }^{6}$ No modelo de repartição simples, as contribuições dos atuais trabalhadores financiam as aposentadorias dos inativos, e as próximas gerações vão financiar os benefícios dos que estão contribuindo.

RER, Rio de Janeiro, vol. 45, no 04, p. 985-1011, out/dez 2007 - Impressa em novembro 2007 
PRORURAL, financiado pelo FUNRURAL, que incluiu trabalhadores rurais e seus dependentes como beneficiários da previdência social. Ao lado do autoritarismo, o milagre econômico foi determinante para a institucionalização das políticas sociais, mostrando a virtuosidade entre a política econômica e a social, já que maior massa salarial possibilitava o alargamento da atuação da proteção social.

A partir de 1974, implementou-se a racionalização dos gastos sociais, ao mesmo tempo em que se objetivava enfatizar a face redistributiva dos programas sociais. Tal racionalidade operacionalizou o SINPAS (Sistema Nacional de Previdência e Assistência Social), aglutinando as agências de arrecadação (IAPAS), de concessão de benefícios (INPS) e serviços médicos (INAMPS). A cobertura continuou se expandindo, cobrindo na década de 1970, em termos previdenciários, $52 \%$ da PEA (5\% do PIB), de acordo com Draibe(1993).

Na primeira metade da década de 1980, o complexo previdenciário foi atingido pelas condições econômicas desfavoráveis, tais como a crise financeira internacional, o ajuste recessivo e as pressões populares por medidas redistributivas; assim combinaram medidas destinadas a reduzir os gastos com benefícios ao mesmo tempo em que ampliavam as carências sociais decorrentes da crise econômica e emergência de temáticas sociais pela democratização. Buscava-se então, resgatar a dívida social herdada do modelo de desenvolvimento econômico anterior que se agravava com a crise econômica do início dos anos 80 .

Fagnani (1997) escreve que esse período foi o do esgotamento de uma estratégia que se iniciou em 1964 e cujos traços estruturais presentes, com maior ou menor força, foram a regressividade dos mecanismos de financiamento (a base de financiamento da previdência era o FPASFundo de Previdência e Assistência Social), a centralização do processo decisório no governo federal (o SINPAS foi exemplo disso) impulsionada pelas reformas institucionais de 1964/1967, a permeabilidade aos interesses privados e uso clientelista (o autor cita as indicações dos agentes para o FUNRURAL e o aumento do número de benefícios concedidos em anos eleitorais), o aumento quantitativo da oferta de serviços sociais (entre 1971 e 1980 o número de segurados inativos urbanos passou de 2,3 milhões para 5,3 milhões), e o reduzido caráter redistributivo. Na previdência social apreende-se esse último aspecto pelo baixo valor dos

RER, Rio de Janeiro, vol. 45, no 04, p. 985-1011, out/dez 2007 - Impressa em novembro 2007 
benefícios, condicionamento do acesso ao benefício, limitada cobertura do trabalhador rural, e privilégios para categorias especiais.

Com o advento da Nova República há um movimento mais intenso no sistema de proteção (Fagnani, 1997) e que culminou com o momento de reestruturação da política social no Brasil, com a Carta de 1988, particularmente no campo trabalhista e da seguridade social.

Sob o conceito de seguridade social foram ampliadas as concepções relativas à previdência, saúde e assistência social, seu modo de financiamento, redefinição dos planos de benefícios e formas de organização que apontam para o aumento na universalização do acesso, dos direitos e da descentralização das ações. No caso da previdência, o texto constitucional contribuiu para a igualização dos benefícios dos trabalhadores urbanos e rurais e alteração de valores, apresentando resultados financeiros satisfatórios até 1994. A partir de 1995 as contas da Previdência Social passaram a ser deficitárias, conforme mostra a Tabela 1. Marques (1997) e Fagnani (1997;1999) apontam para o entendimento desse déficit, como sendo conseqüência de políticas anteriores dos anos 70, e não de ruptura do processo.

Tabela 1 - Evolução do déficit da previdência social - \% do PIB, de 1995 a 2004.

\begin{tabular}{c|cccccccccc}
\hline \multirow{2}{*}{ Déficit } & \multicolumn{10}{|c}{ ANOS } \\
\cline { 2 - 12 } & 1995 & 1996 & 1997 & 1998 & 1999 & 2000 & 2001 & 2002 & 2003 & 2004 \\
\hline Total & 2,8 & 3,8 & 3,7 & 4,4 & 4,7 & 4,8 & 5,3 & 5,2 & 5,6 & 5,3 \\
\hline
\end{tabular}

Fonte: Giambiagi et al. (2004)

No âmbito do orçamento da seguridade pretendia-se integrar dois padrões de financiamento (impostos e contribuição social) e os orçamentos fiscal e da seguridade. Esse último estabelecia como prioridade os direitos sociais. (Dain; Soares, 1998). A implementação dessa medida, no entanto, foi comprometida pela crise econômica e fracasso do governo Collor.

Entre o final de 1988 e início de 1990, fase da regulamentação do processo constitucional, ações ocorreram, principalmente com o financiamento da seguridade, destacando o pagamento dos encargos previdenciários da União com recursos da seguridade e a retenção dos repasses das contribuições sociais pelo Tesouro Nacional (Azeredo apud

RER, Rio de Janeiro, vol. 45, no 04, p. 985-1011, out/dez 2007 - Impressa em novembro 2007 
Fagnani, 1997). Além do mais, por medidas provisórias o Executivo federal ora vinculava ora desvinculava os benefícios previdenciários ao salário mínimo e indexava ao IPC.

A década da democratização e dos avanços na proteção social e de crise econômica terminou sentindo as conseqüências do ajuste recessivo que redundou na crise do Estado e do mercado de trabalho.

Se na década anterior e nos primeiros anos da década de 1990, o volume arrecadado pelas contribuições de empregados e empregadores permitia financiar a totalidade dos benefícios previdenciários, a situação se agravou no pós 94. Podem-se apontar os determinantes dessa situação. De acordo com Marques (1997), houve aumento dos gastos com benefícios de 1992 para 1993 da ordem de 24,4\%, e em relação a 1988 foi de 70,4\%. Concorreram para isso, primeiramente, a existência de demanda reprimida por conta da expectativa de que a Constituição viesse melhorar as condições de acesso e valor dos benefícios, a imposição da justiça brasileira para o pagamento de direitos atrasados, o represamento de pagamentos entre janeiro e outubro de 1992, e, já em 1994, uma ação de antecipação da demanda diante das possíveis mudanças do governo em relação à previdência social.

Em segundo lugar, há que se verificar que os ingressos de novos contribuintes na década de 1970 refletiram num incremento de beneficiários nos anos 90, ao mesmo tempo em que nessa última década modificava-se o mercado de trabalho com reduzida capacidade contributiva. Ramos e Reis (1997) e Ramos e Britto (2004) evidenciam o crescimento da informalidade que passou de $40 \%$ em 1991 para $51 \%$ da população economicamente ativa (PEA) em meados de 2000, baseados nos dados da pesquisa mensal de emprego (PME) do IBGE. O fraco desempenho do emprego assalariado com carteira, e o aumento dos empregadores e dos trabalhadores por conta própria sem contribuição para a previdência são fatos que colaboram para intensificar a problemática vivenciada na década de 1990 .

As políticas passivas e ativas do mercado de trabalho, como as do seguro-desemprego (Azeredo, 1998), qualificação profissional (Souza, 2002), intermediação de mão-de-obra e geração de emprego e renda (Valle, 1998), apresentaram-se insuficientes diante da magnitude da transformação e flexibilidade do mercado de trabalho, uma das faces mais

RER, Rio de Janeiro, vol. 45, no 04, p. 985-1011, out/dez 2007 - Impressa em novembro 2007 
contundentes da exclusão econômica no país (Singer, 1999). Ademais, afetou financeiramente as fontes fiscais e contribuições sociais, fontes de recursos para a política social vinculada ao mercado formal de trabalho.

Além dos problemas expostos, as modificações na estrutura demográfica, envelhecimento da população, tornam-se incompatíveis com as condições de acesso à aposentadoria.?

Inauguram-se, diante desse panorama, as reformas da previdência como a EC $\mathrm{n}^{\circ} 20$ e a lei 9.717/98, que buscavam atingir o regime de previdência do setor público, especialmente. Em 1998, as despesas com esse regime totalizavam $\mathrm{R} \$ 20,9$ bilhões, sendo que a contribuição dos servidores era de R 2,6 bilhões, cobertas pelo Tesouro. No âmbito do regime geral da previdência social, os desequilíbrios financeiros foram evidentes no pós 1994, colaborando para isso a estagnação econômica e as mudanças no mercado de trabalho. Daí que entre 1995 e 1998 viabilizaram-se outras medidas como a substituição do tempo de serviço por tempo de contribuição, o que limita o acesso das camadas mais desfavorecidas diante das características do mercado de trabalho dos anos 90. Diante do comprometimento do ajuste fiscal e da própria estabilização, evidencia-se a urgência das reformas da previdência, favorecidas pelo ambiente de desconforto em relação ao Estado e à esfera pública.

A agenda de Reformas da previdência seguiu para os anos iniciais do século XXI, agora também sustentadas na amplitude dos gastos sociais e na participação das despesas da Previdência nos gastos sociais totais do governo federal, conforme pode-se observar na Tabela 2.

Tabela 2 - Gastos sociais e Despesa com Benefícios do Governo Federal, em percentual do PIB, de 1995 a 2004.

\begin{tabular}{l|c|c|c|c|c|c|c|c|c|c}
\hline \multirow{2}{*}{ Despesas } & \multicolumn{10}{|c}{ ANOS } \\
\cline { 2 - 10 } & 1995 & 1996 & 1997 & 1998 & 1999 & 2000 & 2001 & 2002 & 2003 & 2004 \\
\hline área social & 11,8 & 11,5 & 11,4 & 11,9 & 12,6 & 12,7 & 13,4 & 13,7 & 13,8 & 14,2 \\
$\begin{array}{l}\text { Benefícios, } \\
\text { aposentado- } \\
\text { rias e pen- } \\
\text { sões }\end{array}$ & 7,3 & 7,5 & 7,4 & 8,0 & 8,3 & 8,2 & 8,7 & 8,9 & 9,5 & 9,7 \\
\hline
\end{tabular}

Fonte: Brasil (2005)

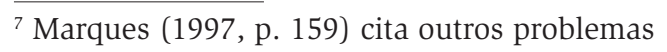




\section{Os resultados da decomposição do índice de gini para o Brasil e Brasil rural}

Com a utilização da metodologia de decomposição do índice de Gini conforme parcelas do rendimento domiciliar per capita, pode-se observar a participação de cada componente na formação do Gini global, para cada ano analisado. Especial atenção é dada ao rendimento das aposentadorias e pensões, objeto de estudo neste trabalho.

A Tabela 3 mostra a participação percentual [(\%) $\left.\phi_{k}\right]$ dos componentes do rendimento domiciliar per capita para o Brasil, no período 1981 a 2003. Observa-se que os rendimentos do trabalho principal contribuem com a maior parcela no total dos rendimentos para o Brasil. Nota-se que o $(\%) \phi_{k}$ é decrescente a partir de 1989.

As aposentadorias e pensões contribuem com a segunda maior parcela no total dos rendimentos. Esse componente, ao longo do período analisado, aumentou a sua participação no valor do rendimento domiciliar per capita.

Tabela 3 - Participação percentual $\left[(\%) \phi_{k}\right]$ dos componentes do rendimento domiciliar per capita. Brasil, de 1981 a 2003.

\begin{tabular}{|c|c|c|c|c|c|c|c|c|c|c|c|c|c|c|c|c|c|c|}
\hline \multirow{2}{*}{ arcelas } & \multicolumn{18}{|c|}{ Brasil - Participação percentual dos rendimentos $\left[(\%) \phi_{k}\right]$} \\
\hline & 1981 & 1983 & 1984 & 1985 & 1986 & 1988 & 1989 & 1990 & 1992 & 1993 & 1995 & 1996 & 1997 & 1998 & 1999 & 2001 & 2002 & 2003 \\
\hline 1 & 82,7 & 81,5 & 81,5 & 82,3 & 83,7 & 84,3 & 82,4 & 81,7 & 79,0 & 78,3 & 78,5 & 78,3 & 78,2 & 76,2 & 75,5 & 74,7 & 74,2 & 3,6 \\
\hline 2 & 2,6 & (3) & 3, & 3,2 & 3,3 & 3,2 & & 3,6 & 2,9 & 3,3 & 3,5 & 3,4 & 3,3 & 3,2 & 3,0 & 3,2 & 3,2 & \\
\hline 3 & 9, & 10,3 & 10,3 & 10,2 & 8,8 & 8 , & 9,8 & 10,7 & 14,2 & 14,1 & 14,2 & 14,5 & 15,2 & 16,7 & 17,8 & 18,5 & 18,7 & \\
\hline 4 & 2,9 & 2,6 & 2,3 & 1,9 & 2,2 & 2,0 & $2, v$ & 2,4 & 1 & 1,1 & 4 & 2,4 & 2,2 & 2,4 & 2,2 & 1,9 & 1,9 & 1,7 \\
\hline 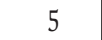 & & - & & & 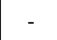 & & & & 0 & 0 & 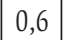 & 0,5 & 0,6 & 0,7 & 0,7 & 0,7 & 0,8 & 0,8 \\
\hline 0 & 2,3 & 2,4 & 2,7 & 2,6 & 2,0 & 2,4 & 2,0 & 1,6 & 2,2 & 2,8 & 0,9 & 0,9 & 0,5 & 0,8 & 0,8 & 0,9 & 1,3 & 1,1 \\
\hline & & & & & & & & & & & & & תח & & & & 100,0 & 100,0 \\
\hline
\end{tabular}

Fonte: Elaboração própria dos autores a partir de IBGE - dados individuais das PNADs de 1981 a 2003.

1 - Trabalho principal; 2 - Outros trabalhos; 3 - Aposentadorias e pensões; 4 - Aluguel; 5 - Doações; 6 - Outros rendimentos.

Para o Brasil, observa-se que entre os anos de 1981 a 1985, a contribuição das aposentadorias e pensões foi de 10,1\%, em média, diminuindo entre 1986 e 1988 (8,5\%) e voltando a crescer a partir de 1989, acentuando 
esse crescimento a partir de 1992 , quando passa de $10,7 \%$ para $14,2 \%$. A partir de 1997 observa-se novamente um crescimento acima da média 1992/1996 (14,3\%), sendo que entre o período 1997/2003, o [(\%) $\left.\phi_{k}\right]$ cresceu continuamente, passando de $15,2 \%$ para $19,8 \%$. Para o período analisado, a participação percentual dos rendimentos das aposentadorias e pensões cresceu 2,1 vezes, passando de 9,5\%, em 1981, para 19,8\% em 2003.

No Brasil rural o $\left[(\%) \phi_{k}\right]$ diminuiu a sua participação entre 1981 e 1986, voltando a crescer a partir de 1988 e destacando-se em 1992, quando passa de 6,7\% (1990) para 15,5\% (1992), aumentando cerca de 2,3 vezes, conforme pode-se observar na Tabela 4 . Vale lembrar que a partir de 1992, com a ampliação das novas leis de custeio e benefício da previdência, o meio rural passa a ter efetivamente acesso à previdência rural, atendendo ao trabalhador rural informal e à agricultura de subsistência. A partir de 1998 observa-se que o $\left[(\%) \phi_{k}\right]$ eleva-se acentuadamente, passando de $17,8 \%$ para $22,4 \%$ em 2003, sendo estes números superiores ao observado no Brasil. Para o período analisado, a participação percentual dos rendimentos das aposentadorias e pensões cresceu 3,6 vezes, passando de 6,2\% em 1981, para 22,4\% em 2003.

Podemos estabelecer mediações a essa análise quantitativa. A primeira metade da década de 1980 viveu a experiência de conjuntura econômica desfavorável, nacional e internacionalmente, com ajustes internos recessivos que passavam por medidas de retenção de gastos com benefícios previdenciários, já que desde 1964 e, particularmente na década de 1970, haviam se expandido por força de uma estratégia de dinamismo social regulada pelo Estado. Dadas as dificuldades de acesso ao benefício e cobertura, aliado ao valor dos benefícios, o que se constata pelos dados elaborados nesta pesquisa é que houve a manutenção da participação das aposentadorias e pensões entre 1981-1985 para o Brasil, cedendo para baixo nos anos imediatamente posteriores, 1986-1989. No âmbito rural esse patamar permaneceu estável, por ainda manter-se limitada a cobertura do trabalhador rural.

No período 1986-1989, o recuo da participação das aposentadorias e pensões indica a resposta da previdência social ao movimento maior no sistema de proteção social do Brasil que finalizou com a Carta Constitucional de 1988. Seus efeitos são visíveis no pós 90, e efetivamente intenso no Brasil rural.

RER, Rio de Janeiro, vol. 45, no 04, p. 985-1011, out/dez 2007 - Impressa em novembro 2007 
Tabela 4 - Participação percentual $\left[(\%) \phi_{k}\right]$ dos componentes do rendimento domiciliar per capita. Brasil Rural, de 1981 a 2003.

\begin{tabular}{c|c|c|c|c|c|c|c|c|c|c|c|c|c|c|c|c|c|c}
\hline \multirow{3}{*}{ Parcelas } & \multicolumn{10}{c|}{ Brasil rural - Participação percentual dos rendimentos $\left[\% \phi_{k}\right]$} \\
\cline { 2 - 17 } & 1981 & 1983 & 1984 & 1985 & 1986 & 1988 & 1989 & 1990 & 1992 & 1993 & 1995 & 1996 & 1997 & 1998 & 1999 & 2001 & 2002 & 2003 \\
\hline 1 & 88,8 & 86,9 & 88,8 & 88,3 & 90,7 & 88,4 & 88,7 & 87,2 & 78,5 & 78,0 & 76,8 & 79,2 & 77,6 & 75,0 & 75,8 & 71,2 & 70,4 & 70,8 \\
2 & 2,3 & 3,7 & 2,5 & 2,4 & 2,1 & 2,5 & 2,8 & 3,4 & 3,4 & 4,4 & 4,7 & 3,8 & 4,1 & 4,2 & 4,0 & 3,7 & 3,5 & 3,0 \\
3 & 6,2 & 6,4 & 6,0 & 6,3 & 5,0 & 5,9 & 6,0 & 6,7 & 15,5 & 14,2 & 15,8 & 14,6 & 15,7 & 17,8 & 17,2 & 21,1 & 21,9 & 22,4 \\
4 & 1,2 & 1,2 & 0,8 & 1,0 & 1,0 & 1,4 & 0,7 & 1,2 & 0,5 & 0,9 & 1,4 & 1,2 & 1,3 & 1,3 & 1,3 & 1,5 & 1,2 & 1,1 \\
5 & - & - & - & - & - & - & - & - & 0,4 & 0,4 & 0,7 & 0,6 & 0,7 & 0,7 & 0,7 & 0,5 & 0,6 & 0,5 \\
6 & 1,6 & 1,8 & 1,8 & 1,9 & 1,2 & 1,8 & 1,8 & 1,4 & 1,7 & 2,2 & 0,7 & 0,7 & 0,6 & 1,0 & 0,9 & 1,9 & 2,4 & 2,2 \\
\hline Total & 100,0 & 100,0 & 100,0 & 100,0 & 100,0 & 100,0 & 100,0 & 100,0 & 100,0 & 100,0 & 100,0 & 100,0 & 100,0 & 100,0 & 100,0 & 100,0 & 100,0 & 100,0 \\
\hline
\end{tabular}

Fonte: Elaboração própria dos autores a partir de IBGE - dados individuais das PNADs de 1981 a 2003.

1 - Trabalho principal; 2 - Outros trabalhos; 3 - Aposentadorias e pensões; 4 - Aluguel; 5 - Doações; 6 - Outros rendimentos.

Ainda assim vale perceber que, embora o número de benefícios tenha crescido 70\%, entre 1988 e 1992, conforme discutido na seção 3 deste trabalho, a participação das aposentadorias e pensões no rendimento domiciliar esteve em torno de $10 \%$ do total de rendimentos para o Brasil, e em percentuais menores, mas mantenedores da mesma situação, o Brasil rural, fase de regulamentação do processo constitucional. A essa fase somam-se medidas provisórias do governo federal e outras ações que retardaram o crescimento da participação da parcela de rendimentos em análise.

A Tabela 5 mostra a razão de concentração dos componentes do rendimento domiciliar per capita, $C\left(x_{k} \mid y\right)$, denotado na tabela como C, para o Brasil. Sabe-se que um componente da renda contribui para aumentar a desigualdade quando a razão de concentração for maior que o índice de Gini.

Para o Brasil, os componentes do rendimento "outros trabalhos" e "aluguéis e juros" (com exceção dos anos de 1985 e 1986) tiveram razão de concentração maior do que o índice de Gini global, e contribuíram para aumentar a desigualdade medida pelo índice de Gini. Os componentes "trabalho principal” e "doações" tiveram razão de concentração menor do que o índice de Gini global, ou seja, em todo o período analisado, esses dois componentes contribuíram para reduzir a desigualdade medida pelo índice de Gini. 
Tabela 5 - Razão de concentração (C) na decomposição do índice de Gini do rendimento domiciliar per capita. Brasil, de 1981 a 2003.

\begin{tabular}{|c|c|c|c|c|c|c|c|c|c|c|c|c|c|c|c|c|c|c|}
\hline \multirow[t]{2}{*}{ Parcelas } & \multicolumn{18}{|c|}{ Brasil - Razão de concentração $C\left(x_{k} \mid y\right)$} \\
\hline & 1981 & 1983 & 1984 & 1985 & 1986 & 1988 & 1989 & 1990 & 1992 & 1993 & 1995 & 1996 & 1997 & 1998 & 1999 & 2001 & 2002 & 2003 \\
\hline 1 & 0,566 & 0,577 & 0,572 & 0,582 & 0,574 & 0,608 & 0,620 & 0,595 & 0,565 & 0,589 & 0,587 & 0,588 & 0,591 & 0,585 & 0,579 & 0,581 & 0,575 & 0,570 \\
\hline 2 & 769 & 0,759 & 0,797 & 0,804 & 0,808 & 0,787 & 0,808 & 0,796 & 0,758 & 0,765 & 0,766 & 0,784 & 0,767 & 0,748 & 0,745 & 0,785 & 0,777 & 0,768 \\
\hline 3 & ,569 & 0,609 & 0,588 & 0,597 & 0,564 & 0,573 & 0,615 & 0,632 & 0,576 & 0,579 & 0,586 & 0,580 & 0,585 & 0,599 & 0,603 & 0,603 & 0,592 & 0 \\
\hline 4 & 778 & 0,797 & 0,812 & 0,812 & 0,833 & 0,801 & 0,882 & 0,820 & 0,802 & 0,784 & 0,813 & 0,802 & 0,796 & 0,803 & 0,803 & 0,797 & 0,803 & 0 \\
\hline 5 & & - & - & 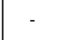 & - & - & - & - & 0,368 & 0,423 & 0,399 & 0,436 & 0,380 & 0,413 & 0,354 & 0,395 & 0,429 & 0,403 \\
\hline 0 & 0,757 & 0,639 & 0,592 & 0,593 & 0,571 & 0,643 & 0,673 & 0,629 & 0,839 & 0,858 & 0,789 & 0,815 & 0,769 & 0,764 & 0,695 & 0,539 & 0,512 & 0,338 \\
\hline tal & 0,582 & 0,594 & 0,587 & 0,595 & 0,586 & \begin{tabular}{|l}
0,616 \\
\end{tabular} & \begin{tabular}{|l}
0,634 \\
\end{tabular} & 0,612 & 0,580 & 0,602 & 0,599 & 0,600 & 0,600 & 0,598 & 0,592 & 0,594 & 0,587 & 0,581 \\
\hline
\end{tabular}

Fonte: Elaboração própria dos autores a partir de IBGE - dados individuais das PNADs de 1981 a 2003. 1 - Trabalho principal; 2 - Outros trabalhos; 3 - Aposentadorias e pensões; 4 - Aluguel; 5 - Doações; 6 - Outros rendimentos.

Para aposentadorias e pensões, a razão de concentração cresceu na primeira metade dos anos 80, recuou em 1986, voltando a crescer a partir de 1988. Nos anos 90, a razão de concentração cresceu entre 1992 e 1995, recuando um pouco em 1996 e voltando a crescer, acentuadamente, no final dos anos 90.

As aposentadorias e pensões apresentaram razão de concentração menor que o índice de Gini global em nove dos 18 anos analisados. Para os anos de 1983, 1984, 1985, 1990, 1998, 1999, 2001, 2002 e 2003, a razão de concentração foi maior que o índice de Gini. Observa-se que, no final da década de 1990 e início do século XXI, as aposentadorias e pensões deram uma contribuição maior para a desigualdade da distribuição do rendimento domiciliar per capita.

Observa-se que, em todo o período analisado, a razão de concentração para aposentadorias e pensões não apresentou recuos significativos. Pelo contrário, a tendência foi de crescimento. A razão de concentração para todos os componentes do rendimento domiciliar per capita foi positiva, mostrando que o valor de todos esses componentes tende a crescer com o rendimento domiciliar per capita.

Note-se que a razão de concentração de aposentadorias e pensões, ao longo do período analisado, é superior ou está ligeiramente abaixo da razão de concentração do rendimento do trabalho principal. O período de 1998 a 2003 apresenta razão de concentração de aposentadorias e pensões supe- 
rior ao índice de Gini e, nos últimos quatro anos, substancialmente maior do que a razão de concentração do rendimento de trabalho principal.

Para o Brasil rural, conforme a Tabela 6, o período entre 1981 e 1990 apresentou razão de concentração abaixo do índice de Gini, não contribuindo para aumentar a desigualdade. Porém, a partir de 1992 esse índice torna-se elevado, e com exceção de 1993, 1996 e 1997, a razão de concentração é superior ao índice de Gini Total, contribuindo para aumentar a desigualdade da renda.

Tabela 6 - Razão de concentração (C) na decomposição do índice de Gini do rendimento domiciliar per capita. Brasil Rural, de 1981 a 2003.

\begin{tabular}{c|c|c|c|c|c|c|c|c|c|c|c|c|c|c|c|c|c|c}
\hline \multirow{2}{*}{ Parcelas } & \multicolumn{10}{c|}{ Brasil Rural - Razão de concentração $C\left(x_{k} \mid y\right)$} \\
\cline { 2 - 12 } & 1981 & 1983 & 1984 & 1985 & 1986 & 1988 & 1989 & 1990 & 1992 & 1993 & 1995 & 1996 & 1997 & 1998 & 1999 & 2001 & 2002 & 2003 \\
\hline 1 & 0,496 & 0,510 & 0,506 & 0,532 & 0,517 & 0,561 & 0,574 & 0,539 & 0,530 & 0,574 & 0,531 & 0,556 & 0,551 & 0,547 & 0,543 & 0,528 & 0,505 & 0,530 \\
2 & 0,593 & 0,523 & 0,578 & 0,578 & 0,609 & 0,644 & 0,712 & 0,700 & 0,608 & 0,607 & 0,606 & 0,646 & 0,603 & 0,454 & 0,542 & 0,623 & 0,515 & 0,518 \\
3 & 0,365 & 0,403 & 0,366 & 0,429 & 0,304 & 0,417 & 0,408 & 0,415 & 0,570 & 0,549 & 0,549 & 0,504 & 0,534 & 0,565 & 0,548 & 0,577 & 0,562 & 0,572 \\
4 & 0,824 & 0,858 & 0,826 & 0,876 & 0,866 & 0,882 & 0,804 & 0,852 & 0,801 & 0,874 & 0,889 & 0,858 & 0,864 & 0,868 & 0,843 & 0,890 & 0,883 & 0,885 \\
5 & - & - & - & - & - & - & - & - & 0,093 & 0,237 & 0,304 & 0,301 & 0,271 & 0,232 & 0,179 & 0,162 & 0,305 & 0,154 \\
6 & 0,727 & 0,641 & 0,622 & 0,655 & 0,549 & 0,593 & 0,648 & 0,586 & 0,816 & 0,844 & 0,718 & 0,821 & 0,746 & 0,581 & 0,500 & 0,101 & 0,112 & 0,040 \\
\hline Total & 0,497 & 0,510 & 0,504 & 0,532 & 0,512 & 0,559 & 0,571 & 0,541 & 0,543 & 0,579 & 0,542 & 0,556 & 0,553 & 0,549 & 0,545 & 0,537 & 0,512 & 0,531 \\
\hline
\end{tabular}

Fonte: Elaboração própria dos autores a partir de IBGE - dados individuais das PNADs de 1981 a 2003. 1 - Trabalho principal; 2 - Outros trabalhos; 3 - Aposentadorias e pensões; 4 - Aluguel; 5 - Doações; 6 - Outros rendimentos.

A Tabela 7 mostra a participação de cada componente para a formação do índice de Gini e a sua participação, em termos percentuais, para a formação do índice de Gini global no Brasil. Observa-se que o rendimento do trabalho principal é, em todo o período, o componente com a maior participação na formação do índice de Gini do rendimento domiciliar per capita, seguido pelo rendimento de aposentadorias e pensões.

Ao longo do período analisado, verifica-se que os rendimentos do trabalho principal, em média, representam $79,3 \%$ do rendimento total e originam a maior parcela do índice de Gini, participando com 77,5\% . 
Tabela 7 - Parcelas do índice de Gini $\left[\oint_{k} C\left(x_{k} \mid y\right)\right]$ na formação do índice de Gini Global dos componentes do rendimento domiciliar per capita. Brasil, de 1981 a 2003.

\begin{tabular}{|c|c|c|c|c|c|c|c|c|c|c|c|c|c|c|c|c|c|c|}
\hline \multirow[t]{2}{*}{ Parcelas } & \multicolumn{18}{|c|}{ Brasil - Parcelas do Índice de Gini $\left[\phi_{k} C\left(x_{k} \mid y\right)\right]$} \\
\hline & 1981 & 1983 & 1984 & 1985 & \begin{tabular}{|l|}
1986 \\
\end{tabular} & 1988 & \begin{tabular}{|l|}
1989 \\
\end{tabular} & 1990 & 1992 & 1993 & 1995 & 1996 & 1997 & 1998 & \begin{tabular}{|l|}
1999 \\
\end{tabular} & 2001 & 2002 & 2003 \\
\hline 1 & 0,468 & 0,471 & 0,467 & 0,479 & 0,480 & 0,512 & 0,511 & 0,486 & 0,446 & 0,461 & 0,461 & 0,461 & 0,462 & 0,446 & 0,437 & 0,434 & 0,426 & 0,419 \\
\hline 2 & 0,020 & 0,025 & 0,025 & 0,025 & 0,026 & 0,025 & 0,028 & 0,029 & 0,022 & 0,025 & 0,027 & 0,027 & 0,025 & 0,024 & 0,022 & 0,025 & 0,025 & 0,024 \\
\hline 3 & 0,054 & 0,060 & 0,060 & 0,061 & 0,050 & 0,047 & 0,060 & 0,068 & 0,081 & 0,082 & 0,083 & 0,084 & 0,089 & 0,100 & 0,107 & 0,112 & 0,111 & 0,118 \\
\hline 4 & 0,022 & & 0,019 & 0,015 & 0,019 & 0,016 & 0,021 & 0,019 & 0,011 & 0,009 & 0,018 & 0,019 & 0,017 & 0,019 & 0,018 & 0,015 & 0,015 & 0,014 \\
\hline 5 & - & - & - & - & - & - & - & - & 0,002 & 0,002 & 0,002 & 0,002 & 0,002 & 0,003 & 0,002 & 0,003 & 0,003 & 0,003 \\
\hline 6 & 0,017 & 0,016 & 0,016 & 0,015 & 0,011 & 0,015 & 0,014 & 0,010 & 0,018 & 0,023 & 0,007 & 0,007 & 0,005 & 0,006 & 0,006 & 0,005 & 0,007 & 0,004 \\
\hline Total & 0,582 & 0,587 & 0,587 & 0,595 & 0,586 & 0,616 & \begin{tabular}{|l|}
0,634 \\
\end{tabular} & 0,612 & 0,580 & 0,602 & 0,599 & 0,600 & 0,600 & 0,598 & 0,592 & 0,594 & 0,587 & 0,581 \\
\hline
\end{tabular}

Entre os demais componentes do rendimento, as aposentadorias e pensões vêm a seguir, representando, em média, 13,4\% do rendimento total, originando a segunda maior parcela do índice de Gini. Em 1981, a contribuição dessa parcela para o índice de Gini foi de 9,3\%. Essa participação foi razoavelmente estável no período de 1981 a 1985, diminuiu de 1986 a 1988 e voltou a crescer a partir de 1989, quando contribuiu com 9,5\%. Em 1992, a contribuição dessa parcela para o índice de Gini total passa a ser de $14 \%$, acentuando esse crescimento na segunda metade dos anos 90, principalmente nos anos de 1998 e 1999. A sua participação cresce ainda mais em 2002, quando atinge 20,3\% do índice de Gini, sendo esse o maior percentual de todo o período de 1981 a 2003.

Entre 1992 e 2003, a parcela do índice de Gini do rendimento domiciliar per capita referente ao rendimento do trabalho principal, diminuiu 0,027, ao mesmo tempo que a parcela referente ao rendimento de aposentadorias e pensões aumentou 0,037.

Portanto, as aposentadorias e pensões contribuem significativamente na formação do índice de Gini em todo o período analisado, com clara tendência de crescimento na década de 1990 e início do atual século.

No Brasil rural, conforme pode-se ver na Tabela 8, a parcela de aposentadorias e pensões participou também com a segunda maior parcela 
do índice de Gini Total. Entre 1981 e 1990 essa participação foi relativamente estável. A partir de 1992 nota-se um crescimento acentuado, passando de 5,1\% em 1990 para 16,4\% em 1992. A partir de 1992 e ao longo dos anos 90 essa participação foi crescente, chegando em 1999 com 17,5\%. Os anos de 2001, 2002 e 2003 apresentam as maiores participações desse componente no índice de Gini Total, superando o Brasil. Entre 1992 e 2003, no Brasil Rural, a parcela do rendimento do trabalho principal diminuiu 0,05, enquanto a parcela do rendimento de aposentadorias e pensões cresceu 0,04.

Como demonstram os dados, há significativa contribuição das aposentadorias e pensões para a concentração de renda no Brasil na década de 1980, exceto para a área rural. Observa-se o caráter não distributivo da previdência social no período, ou seja, construiu-se uma esfera pública particularmente importante em termos de proteção social, mas, como já adianta a literatura sobre o tema, com resultados pouco significativos para reduzir desigualdades. Este trabalho mostra, quantitativamente, a magnitude da parcela para a concentração de renda.

Tabela 8 - Parcelas do índice de Gini $\left.\oint_{k} C\left(x_{k} \mid y\right)\right]$ na formação do índice de Gini Global dos componentes do rendimento domiciliar per capita.

Brasil Rural, de 1981 a 2003.

\begin{tabular}{c|c|c|c|c|c|c|c|c|c|c|c|c|c|c|c|c|c|c}
\hline & \multicolumn{10}{c|}{ Parcelas } \\
\cline { 2 - 16 } & 1981 & 1983 & 1984 & 1985 & 1986 & 1988 & 1989 & 1990 & 1992 & 1993 & 1995 & 1996 & 1997 & 1998 & 1999 & 2001 & 2002 & 2003 \\
\hline 1 & 0,439 & 0,443 & 0,450 & 0,470 & 0,469 & 0,496 & 0,509 & 0,470 & 0,416 & 0,447 & 0,407 & 0,440 & 0,427 & 0,410 & 0,411 & 0,376 & 0,356 & 0,376 \\
2 & 0,014 & 0,019 & 0,014 & 0,014 & 0,013 & 0,016 & 0,020 & 0,024 & 0,020 & 0,027 & 0,028 & 0,024 & 0,025 & 0,019 & 0,022 & 0,023 & 0,018 & 0,016 \\
3 & 0,022 & 0,026 & 0,022 & 0,027 & 0,015 & 0,024 & 0,025 & 0,028 & 0,08 & 0,078 & 0,087 & 0,074 & 0,084 & 0,101 & 0,094 & 0,122 & 0,123 & 0,128 \\
4 & 0,010 & 0,011 & 0,007 & 0,009 & 0,008 & 0,012 & 0,005 & 0,010 & 0,004 & 0,008 & 0,013 & 0,010 & 0,012 & 0,012 & 0,011 & 0,014 & 0,010 & 0,010 \\
5 & - & - & - & - & - & - & - & - & & 0,001 & 0,002 & 0,002 & 0,002 & 0,002 & 0,001 & 0,001 & 0,002 & 0,001 \\
6 & 0,011 & 0,012 & 0,011 & 0,013 & 0,007 & 0,011 & 0,012 & 0,008 & 0,014 & 0,019 & 0,005 & 0,006 & 0,005 & 0,006 & 0,005 & 0,002 & 0,003 & 0,001 \\
\hline Total & 0,497 & 0,510 & 0,504 & 0,532 & 0,512 & 0,559 & 0,571 & 0,541 & 0,543 & 0,579 & 0,542 & 0,556 & 0,553 & 0,549 & 0,545 & 0,537 & 0,512 & 0,531 \\
\hline
\end{tabular}

Fonte: Elaboração própria dos autores a partir de IBGE - dados individuais das PNADs de 1981 a 2003. 1 - Trabalho principal; 2 - Outros trabalhos; 3 -Aposentadorias e pensões; 4 -Aluguel; 5 - Doações; 6 - Outros rendimentos.

No entanto, é necessário insistir, na área rural não se observa a contribuição das aposentadorias para aumentar a concentração de renda do- 
miciliar na década de 1980. Além disso, embora crescentes, os índices de Gini para essas regiões são menores do que para o Brasil como um todo.

Na década de 1990 e nos anos que a seguiram têm-se vivenciado uma intensificação no processo de concentração de renda nas regiões analisadas, com detalhamentos relevantes. Houve aumento da participação das aposentadorias e pensões nos rendimentos e queda na participação do rendimento do trabalho. No âmbito do mercado de trabalho, como já se teve ocasião de expor, a sua desestruturação e vulnerabilidade recentes explicam, em grande parte, esse fenômeno.

O aumento visível das aposentadorias é resultado do conteúdo favorável à seguridade social da Constituição de 1988 e do aumento do volume de contribuintes estimulado na década de 1970 que redundou no incremento de beneficiários na década de 1990, das mudanças demográficas, da queda na taxa de natalidade e do "envelhecimento" da população brasileira. Especial atenção é merecedora a área rural brasileira, com expressivos incrementos na participação das aposentadorias na renda domiciliar. Os anos 90-92 são ímpares, dada a magnitude de elevação dessa participação.

Frente à evolução dessa situação, aliada às políticas econômicas do período, que comprometiam os resultados financeiros da previdência social, medidas são tomadas para freá-la na década de 1990. Mesmo assim, ocorre com um novo ímpeto o seu aumento no período 1998-2003, o que desembocou nas propostas recentes de Reforma da Previdência.

A preocupação maior, além do embaraço financeiro da previdência social, é que as aposentadorias e pensões voltaram a contribuir para a concentração de renda no pós 98, e com um agravante, isso passa a ocorrer também na área rural do país.

\section{Considerações finais}

A previdência social esteve restrita aos setores urbanos organizados dos trabalhadores e a algumas categorias profissionais, da sua criação até o início dos anos 60, não tendo o sentido de universalização. Após 1964, o sistema de proteção social e a previdência social passam por reformas e são direcionadas a unificação e universalização dos benefícios, incluindo em 1971 os trabalhadores rurais. Apesar disso, o que

RER, Rio de Janeiro, vol. 45, no 04, p. 985-1011, out/dez 2007 - Impressa em novembro 2007 
constatou no período foi concentração de renda e reprodução de desigualdade, uma vez que o gasto social foi financiado por contribuições sociais, fundadas na capacidade contributiva do trabalhador.

Nos primeiros anos da década de 1980 o país atravessou condições econômicas internas e externas bastante desfavoráveis, marcadas pelo esgotamento dos mecanismos de financiamento da previdência pelo Estado, centralização do processo decisório sobre a previdência, interesses privados, aumento quantitativo da oferta de serviços sociais e o reduzido caráter redistributivo. Observa-se que nesse período as razões de concentração das aposentadorias e pensões para os anos de 1983 a 1985 são superiores ao índice de Gini para o Brasil, contribuindo para aumentar a desigualdade de renda.

Nos anos 80 a cobertura do trabalhador rural ainda era bastante limitada, e as razões de concentração de aposentadorias e pensões no Brasil Rural são menores que o índice de Gini na área rural.

Na segunda metade dos anos 80 temos uma reestruturação da política social brasileira, através da Constituição de 1988. Particularmente, a previdência foi modificada no seu modo de financiamento, nos planos de benefícios, na universalização do acesso, na igualdade dos benefícios dos trabalhadores rurais e urbanos, além de corrigir os valores das aposentadorias e pensões.

Com a exceção de 1990, observa-se que de 1985 a 1997, as razões de concentração das aposentadorias e pensões mostram que essa parcela do rendimento não estava contribuindo para aumentar a desigualdade de renda no Brasil. Com relação ao Brasil Rural, o ano de 1992 apresenta razão de concentração maior que o índice de Gini Total, evidenciando a implantação da nova legislação previdenciária, beneficiando o acesso de milhões de trabalhadores rurais e pequenos produtores rurais às aposentadorias e pensões.

Na primeira metade dos anos 90, o volume arrecadado pelas contribuições de empregados e empregadores permitiu financiar a totalidade dos benefícios previdenciários. Porém, após 1994 a situação se agravou devido a: aumento de gastos com benefícios, aumento no número de beneficiários, crescimento da informalidade, modificações na estrutura demográfica e envelhecimento da população. Esses fatores, aliados à falta de crescimento da economia, levaram ao déficit crescente da previdência.

RER, Rio de Janeiro, vol. 45, no 04, p. 985-1011, out/dez 2007 - Impressa em novembro 2007 
Observa-se que a partir de 1998 a razão de concentração das aposentadorias e pensões é superior ao índice de Gini Global para o Brasil e Brasil rural.

Esses resultados mostram que os rendimentos de aposentadorias e pensões, administrados pelo governo federal, estão contribuindo para aumentar a desigualdade da distribuição da renda no Brasil. As tentativas de reforma do sistema previdenciário realizadas pós 1998 mostraram-se incapazes de solucionar as suas distorções, pelo menos no curto prazo. É importante notar que um componente dos rendimentos que está diretamente sujeito a normas e leis, como as aposentadorias e pensões, esteja contribuindo para aumentar a desigualdade da distribuição da renda.

\section{Referências bibliográficas}

AZEREDO, B. Políticas públicas de emprego: a experiência brasileira. São Paulo: ABET, 1998.

BRASIL. Ministério da Fazenda. Secretaria de Política Econômica. Orçamento social do governo federal: 2001-2004. Brasília, 2005.

DAIN, S; SOARES, L. T. Reforma do Estado e políticas públicas: relações intergovernamentais e descentralização desde 1988. In: OLIVEIRA, M. A.(org.). Reforma do Estado e políticas de emprego no Brasil. Campinas: Unicamp, 1998.

DRAIBE, S. M. Qualidade de vida e reformas de programas sociais: o Brasil no cenário latino-americano. Lua Nova, n.31, 1993.

ERCELAWN, A. Income inequality in rural Pakistan: a study of sample villages. Pakistan Journal of Applied Economics, n.3, p.1-28, 1984.

FAGNANI, E. Ajuste econômico e financiamento da política social brasileira: notas sobre o período 1993/98. Economia e sociedade, Campinas, n.13, p.155-178, dez.1999.

-------, E. Política social e pactos conservadores no Brasil: 1964/92. Economia e sociedade, Campinas, n.8, p.183-238, jun.1997.

FEI, J.C.; RANIS, G.; KUO, S.W.Y. Growth and the family distribution of income by factor components. The Quarterly Journal of Economics, v.92, p.17-53, Feb. 1978.

RER, Rio de Janeiro, vol. 45, no 04, p. 985-1011, out/dez 2007 - Impressa em novembro 2007 
FERREIRA, C. R. Participação das aposentadorias e pensões na desigualdade da distribuição da renda no Brasil no período de 1981 a 2001 . Piracicaba, 2003. 136p.Tese (Doutorado) - Escola Superior de Agricultura “Luiz de Queiroz”, Universidade de São Paulo.

GIAMBIAGI, F. et al. Diagnóstico da previdência social no Brasil: o que foi feito e o que falta reformar? Rio de Janeiro: IPEA, 2004. 44 p. (Texto para Discussão, 1050).

HOFFMANN, R. A subdeclaração dos rendimentos. São Paulo em Perspectiva - SEADE, v.2, n.1, p.50-54, jan/mar. 1988.

HOFFMANN, R. Desigualdade no Brasil: a contribuição das aposentadorias. www.eco.unicamp.br/projetos/rurbano.html. (17 out. 2002a)

HOFFMANN, R. Posse da terra, renda e condições de vida na agricultura brasileira (compact disc). In: CONGRESSO BRASILEIRO DE ECONOMIA E SOCIOLOGIA RURAL, 40., Passo Fundo, 2002. Anais. Brasília: SOBER, 2002b.

HOFFMANN, R. Inequality in Brazil: the contribution of pensions. Revista Brasileira de Economia. v. 57, n.4, p.755-773. out/dez. 2003.

IBGE - INSTITUTO BRASILEIRO DE GEOGRAFIA E ESTATÍSTICA. Pesquisa Nacional por Amostra de Domicílios (compact disc). Rio de Janeiro, 1981, 1983-86, 1988-89, 1990, 1992-93, 1995-99, 2001, 2002 e 2003.

MARIANO, J.L.; LIMA, R.C. A desigualdade da renda rural no Nordeste: análise da desagregação do coeficiente de Gini e da sensibilidade do índice de bem-estar de Sen. Análise Econômica, v.16, n.29, p.103-118, mar. 1998.

MARQUES, R. M. A proteção social e o mundo do trabalho. São Paulo: Bienal, 1997.

NEDER, H.D. Os efeitos das atividades não-agrícolas na distribuição de renda no meio rural (compact disc). In: CONGRESSO BRASILEIRO DE ECONOMIA E SOCIOLOGIA RURAL, 39., Recife, 2001. Anais. Brasília: SOBER, 2001. 
PYATT, G.; CHEN, C.; FEI, J. The distribution of income by factor components. The Quarterly Journal of Economics, v.95, n.3, p.451-473, Nov. 1980.

RAMOS, L; BRITTO, M. 0 funcionamento do mercado de trabalho metropolitano brasileiro no período 1991-2002: tendências, fatos estilizados e mudanças estruturais. Rio de Janeiro: IPEA, 2004.

RAMOS, L; REIS, J. G. A. Emprego no Brasil nos anos 90. Rio de Janeiro, IPEA, 1997.

SINGER, P. Globalização e desemprego:diagnóstico e alternativas. São Paulo: Contexto, 1999.

SOUZA, S. C. I. A qualificação do trabalhador e a política pública de emprego e trabalho. Tese (Doutorado), Pontifícia Universidade Católica de São Paulo, 2002.

VALLE, B. Políticas de mercado de trabalho no Brasil: a experiência do Proger. In: OLIVEIRA, M. A.(org.). Reforma do Estado e políticas de emprego no Brasil. Campinas: Unicamp, 1998.

Recebido em março de 2006 e revisto em outubro de 2006. 